\title{
Corpus Asher-Greve. Dealing with "Data from the Past"
}

SNF-Project (1.722-0.83): Naturwissenschaftliche und typologische Untersuchungen an Rollsiegeln.

When? 1983-1986

Who? Dr. Julia Asher-Greve and Prof. Dr. Willem Stern, University of Basel

Material? 1017 cylinder seals from Mesopotamia and neighbouring regions covering all periods from Uruk to Achaemenid period.

What? - XRD (X-ray diffraction)

$\rightarrow$ mineralogical composition

- EDXRF (energy dispersive X-ray fluorescence)

$\rightarrow$ chemical composition

- Iconographical typology

Project couldn't be brought to an end, data not interpreted

PhD-Project based on the corpus and analyses of the project AsherGreve

When? 2017-2020 (?)

Who? Nicole Gäumann

Material? Same

What? - Interpretation of XRD- and EDXRF from previous project

- Further analyses on existing powder samples (?)

- Typology

Bringing together the results of the material analyses and the archaeological data, the material ought to be interpreted in terms of connections between material, colour, dating, provenance, theme, owner... 